\title{
molecules
}

ISSN 1420-3049

www.mdpi.com/journal/molecules

Article

\section{Isolation and Characterization of a New Ginsenoside from the Fresh Root of Panax Ginseng}

\section{Chang-Chun Ruan ${ }^{1,2}$, Zhi Liu ${ }^{1}$, Xiang Li ${ }^{3,4}$, Xia Liu ${ }^{2, *}$, Li-Juan Wang ${ }^{2}$, Hong-Yu Pan ${ }^{4}$, Yi-Nan Zheng ${ }^{2}$, Guang-Zhi Sun ${ }^{1}$, Yan-Sheng Zhang ${ }^{5}$ and Lian-Xue Zhang ${ }^{2, *}$}

1 Institute of Agricultural Modernization, Jilin Agricultural University, Changchun, 130118, China; E-Mails: ccyuan@yahoo.com (C.C.R.); 1zhiiu@126.com (Z.L.); gzsun1967@126.com (G.Z.S.)

2 College of Chinese Medicinal Materials, Jilin Agricultural University, Changchun, 130118, China; E-Mails: ljwang@yahoo.com(L.J.W.); zhenyinan@tom.com (Y.N.Z.)

3 Agriculture and Agri-Food Canada, Saskatoon Research Center, 107 Science Place, Saskatoon, S7N 0X2, SK, Canada; E-Mail: drxiang@hotmail.com (X.L.)

4 College of Plant Science, Jilin University, Changchun, 130062, China;

E-Mail: panhongyu@jlu.edu.cn (H.Y.P.)

5 Wuhan Botanical Garden, Chinese Academy of Sciences, Wuhan, 430074, China;

E-Mail: zhangys@wbgcas.cn (Y.S.Z.)

* Authors to whom correspondence should be addressed; E-Mails: jlndzyc@126.com (X.L.); zh.lianxue@gmail.com (L.X.Z.)

Received: 8 March 2010; in revised form: 23 March 2010 / Accepted: 26 March 2010 /

Published: 30 March 2010

Abstract: A new saponin, malonylginsenoside $\mathrm{Ra}_{3}$, was isolated from the fresh root of Panax ginseng, along with four known ginsenosides. The new compound was identified as (20S)-protopanaxadiol-3- $O$-(6- $O$-malonyl- $\beta$-D-glucopyranosyl $(1 \rightarrow 2)-\beta$-D-glucopyranoside -20- $O$ - $\beta$-D-xylopyranosyl $(1 \rightarrow 3)$ - $\beta$-D-glucopyranosyl $(1 \rightarrow 6)-\beta$-D-glucopyranoside on the basis of extensive 1D and 2D NMR as well as HRESI-MS spectroscopic data analysis.

Keywords: Panax ginseng; ginsenoside; malonyl-ginsenoside $\mathrm{Ra}_{3}$ 


\section{Introduction}

Panax ginseng C.A. Meyer has been used in China for thousands of years as a traditional medicine and proved to exhibit wide pharmacological properties, such as anti-fatigue, anti-diabetes, as well as activity in the prevention of cancer and the ageing process [1-4]. The major components contributing to its pharmacology activities were considered to be the ginsenosides, a group of steroidal saponins. Around 40 ginsenosides have been isolated and characterized till now, including the recent identified ginsenosides $\mathrm{Ki}$ and $\mathrm{Km}$ [5]. Among these known compounds, malonylginsenosides are natural ginsenosides that exist in both fresh and air-dried ginseng roots and which contain malonyl residues attached to the glucose units of the corresponding neutral ginsenosides [6]. Kitagawa et al. and Yamaguchi et al. reported the presence of four acidic ginsenosides both in Asian and American ginseng [7,8]. Our previous pharmacology results showed that total malonyl-ginsenosides exhibit hypoglycemic effects on streptozotocin-induced diabetic mice [9]. During our continued studies on bioactive compounds from Panax ginseng [10-12], a novel ginsenoside, namely malonylginsenoside $\mathrm{Ra}_{3}$ (compound 1), was isolated from a methanolic extraction of the fresh roots of Panax ginseng. This paper describes the isolation and structure determination of the new compound $\mathbf{1}$ (Figure 1).

Figure 1. The structures of the isolated ginsenosides.

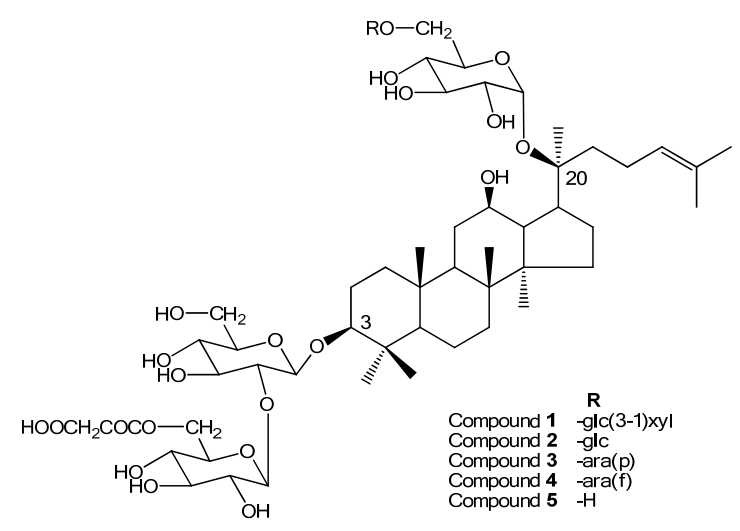

\section{Results and Discussion}

A crude methanolic extract of the fresh roots of Panax ginseng was subjected to open column chromatography on silica gel and then purified by preparative HPLC, to yield five ginsenosides, one of which, namely malonylginsenoside $\mathrm{Ra}_{3}$ (compound 1), was new. The other four saponins were identified as known malonylginsenoside- $\mathrm{Rb}_{1}$ (compound 2 ), malonylginsenoside- $\mathrm{Rb}_{2}$ (compound $\mathbf{3}$ ), malonylginsenoside-Rc (compound 4) and malonylginsenoside-Rd (compound 5) by comparison of NMR data with those in the literature [6] and by comparison with authentic sample by ESI-MS, optical rotation and TLC.

\section{Characterization of compound $\mathbf{1}$}

Compound 1 was obtained as a white amorphous powder and gave a peaks at $m / z 1325.4[\mathrm{M}-\mathrm{H}]^{-}$,

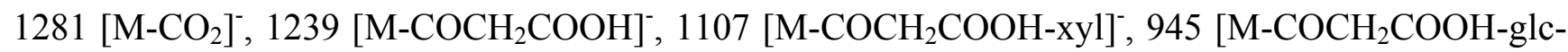
$\mathrm{xyl}]^{-}, \quad 783 \quad\left[\mathrm{M}-\mathrm{COCH}_{2} \mathrm{COOH}-\mathrm{xyl}-2 \mathrm{glc}-\mathrm{H}\right]^{-}, \quad 621 \quad\left[\mathrm{M}-\mathrm{COCH}_{2} \mathrm{COOH}-\mathrm{xyl}-3 \mathrm{glc}-\mathrm{H}\right]^{-}, \quad 459 \quad[\mathrm{M}-$ 
$\left.\mathrm{COCH}_{2} \mathrm{COOH}-\mathrm{xyl}-4 \mathrm{glc}-\mathrm{H}\right]^{-}$, in the negative ESI-MS, indicating its molecular weight to be 1326 . The molecular formula was determined as $\mathrm{C}_{62} \mathrm{H}_{102} \mathrm{O}_{30}$ based on HRESI-MS [M+Na] ${ }^{+}: m / z \quad 1349.6348$ $[\mathrm{M}+\mathrm{Na}]^{+}$(calcd. for $\left.\mathrm{C}_{62} \mathrm{H}_{102} \mathrm{NaO}_{30}, 1349.6353\right)$. IR $(\mathrm{KBr}) v_{\max } / \mathrm{cm}^{-1}: 3423 \mathrm{~cm}^{-1}(\mathrm{OH}), 1732 \mathrm{~cm}^{-1}(\mathrm{C}=\mathrm{O})$, $1608(\mathrm{C}=\mathrm{C})$ and $1386 \mathrm{~cm}^{-1}\left(-\mathrm{CH}_{3}\right)$. Since compound 1 can't be dissolved in pyridine- $d_{5}$, we added 0.1 $\mathrm{mL}$ of $\mathrm{D}_{2} \mathrm{O}$ in $0.5 \mathrm{~mL}$ of pyridine- $d_{5}$ as NMR solvent. Ginsenoside $\mathrm{m}-\mathrm{Rb}_{1}$ (compound 2) and the alkaline hydrolysis product of $\mathbf{1}$, ginsenoside $\mathrm{Ra}_{3}$ (compound $\mathbf{1 a}$ ) were also dissolved in the same mixture solvent for NMR measurement. Analysis of the ${ }^{13} \mathrm{C}-\mathrm{NMR}$ spectrum (Table 1) and DEPT experiments, allowed the identification of eight methyl groups and six quaternary carbons.

Table 1. The ${ }^{13} \mathrm{C}-\mathrm{NMR}$ data of compounds 1, 2 and 1a. ${ }^{\mathrm{a}}$

\begin{tabular}{|c|c|c|c|c|c|c|c|}
\hline & 1 & 2 & $1 a$ & & 1 & 2 & $1 a$ \\
\hline C-1 & 40.0 & 40.1 & 39.3 & 3-Glu & & & \\
\hline $\mathrm{C}-2$ & 27.7 & 27.6 & 26.7 & C-1' & 105.5 & 105.8 & 105.0 \\
\hline C-3 & 90.9 & 90.7 & 89.0 & $\mathrm{C}-2$ & 85.1 & 84.8 & 83.5 \\
\hline C-4 & 40.6 & 40.6 & 39.6 & $\mathrm{C}-3^{\prime}$ & 78.5 & 78.5 & 78.0 \\
\hline C-5 & 57.4 & 57.4 & 56.5 & C-4' & 72.2 & 72.2 & 71.6 \\
\hline C-6 & 19.4 & 19.4 & 18.4 & $\mathrm{C}-5$ & 78.5 & 78.8 & 78.0 \\
\hline C-7 & 36.0 & 36.0 & 35.1 & C-6' & 63.4 & 63.4 & 62.8 \\
\hline C-8 & 40.9 & 41 & 40.0 & Glu & & & \\
\hline C-9 & 51.0 & 51.1 & 50.1 & C-1" & 106.3 & 106.5 & 105.9 \\
\hline $\mathrm{C}-10$ & 37.8 & 37.8 & 36.8 & C-2" & 77.4 & 77.5 & 77.1 \\
\hline $\mathrm{C}-11$ & 31.2 & 31.3 & 30.9 & C-3" & 79.5 & 79.4 & 79.2 \\
\hline $\mathrm{C}-12$ & 71.0 & 70.9 & 70.1 & C-4" & 71.6 & 71.7 & 71.6 \\
\hline $\mathrm{C}-13$ & 50.0 & 50.2 & 49.3 & C-5" & 75.7 & 75.8 & 78.0 \\
\hline C-14 & 52.5 & 52.4 & 51.4 & C-6" & 66.1 & 66.1 & 62.8 \\
\hline C-15 & 31.8 & 31.9 & 30.9 & 20-Glu & & & \\
\hline C-16 & 27.7 & 27.6 & 26.6 & $\mathrm{C}-1$ ' & 98.7 & 98.8 & 98.1 \\
\hline C-17 & 52.8 & 52.8 & 51.7 & $\mathrm{C}-2$ & 75.3 & 75.6 & 74.8 \\
\hline C-18 & 17.2 & 17.2 & 16.3 & $\mathrm{C}-3$ & 78.5 & 78.8 & 78.0 \\
\hline C-19 & 16.9 & 16.9 & 16.0 & C-4, & 72.2 & 72.2 & 71.6 \\
\hline $\mathrm{C}-20$ & 85.2 & 85.0 & 83.5 & $\mathrm{C}-5$ & 77.4 & 77.2 & 77.1 \\
\hline $\mathrm{C}-21$ & 23.3 & 23.3 & 22.7 & C-6' & 70.4 & 72 & 69.6 \\
\hline $\mathrm{C}-22$ & 37.2 & 37.1 & 36.1 & Glu & & & \\
\hline $\mathrm{C}-23$ & 24.3 & 24.2 & 23.3 & C-1" & 105.5 & 105.6 & 105.0 \\
\hline $\mathrm{C}-24$ & 126.7 & 126.8 & 126.0 & C-2" & 74.7 & 75.6 & 74.2 \\
\hline $\mathrm{C}-25$ & 132.8 & 132.6 & 130.8 & C-3" & 88.0 & 78.8 & 87.4 \\
\hline $\mathrm{C}-26$ & 26.9 & 26.8 & 25.8 & C-4" & 71.7 & 72.2 & 71.3 \\
\hline $\mathrm{C}-27$ & 19.0 & 19.0 & 17.9 & C-5" & 78.5 & 78.8 & 78.0 \\
\hline C-28 & 29.0 & 29.0 & 28.1 & C-6" & 63.0 & 63.4 & 62.4 \\
\hline C-29 & 17.5 & 17.5 & 16.5 & Xyl & & & \\
\hline $\mathrm{C}-30$ & 18.3 & 18.3 & 17.3 & C-1", & 106.6 & & 106.2 \\
\hline$-\mathrm{O}-\underline{\mathrm{CO}}$ & 172.1 & 171.9 & & C-2,", & 75.7 & & 75.2 \\
\hline
\end{tabular}


Table 1. Cont.

\begin{tabular}{cccccc}
\hline $\mathrm{CH}_{2}$ & 41.9 & 41.9 & $\mathrm{C}-3{ }^{\prime \prime}$, & 77.4 & 77.1 \\
$\underline{\mathrm{COOH}}$ & 174.6 & 174.5 & $\mathrm{C}-4,{ }^{\prime}$, & 71.2 & 70.8 \\
& & & $\mathrm{C}-5{ }^{\prime}$, & 67.8 & 67.2 \\
\hline
\end{tabular}

${ }^{\text {a }}$ Compounds $\mathbf{1}, \mathbf{1 a}$ and 2 were measured in $\mathrm{C}_{5} \mathrm{~N}_{5}-d_{6}(0.5 \mathrm{~mL})$ plus $\mathrm{D}_{2} \mathrm{O}(0.1 \mathrm{~mL})$.

The ${ }^{1} \mathrm{H}$ - and ${ }^{13} \mathrm{C}-\mathrm{NMR}$ spectroscopic data of compound 1 were similar to those of ginsenoside-Ra [13], except the data attributed to a malonyl group $\left(\delta_{\mathrm{H}} 3.70, \delta_{\mathrm{C}} 172.1, \delta_{\mathrm{C}} 174.6\right)$. The malonyl group was assigned to $\mathrm{C}_{3}$-glc-C-6" position by HMBC experiment (Figure 2), which the protons of $\mathrm{C}_{3}$-glcH-6" showed HMBC correlations with malonyl group $\left(\delta_{\mathrm{C}} 172.1\right)$.

Figure 2. Partial HMBC correlation of compound 1.

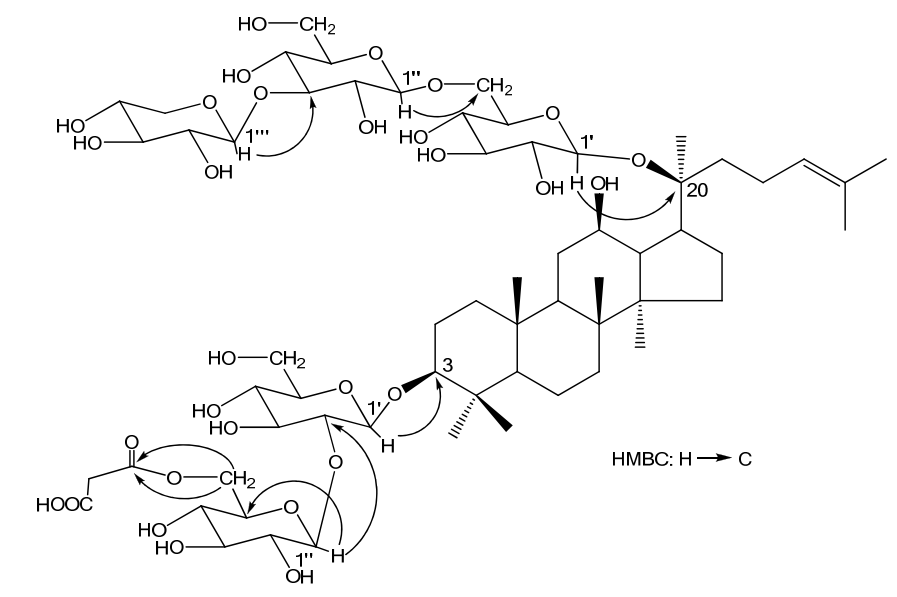

Malonyl group connection also caused a 2.7 ppm lower-field shift for $\mathrm{C}_{3}$-glc-C-6" ${ }^{\prime}\left(\delta_{\mathrm{C}} 66.1\right)$ than seen in ginsenoside- $\mathrm{Ra}_{3}$. Alkaline hydrolysis of compound $\mathbf{1}$ yield compound $\mathbf{1 a}$, which showed the structure identical to ginsenoside $\mathrm{Ra}_{3}$ by $1 \mathrm{D}$ NMR analysis (Table 1). The absolute configurations of the sugar moieties were further determined to be $\beta$-D-glucose and $\beta$-D-xylose by chiral GC analysis. The 20 position was determined as $S$ conformation due to its similar NMR data with the known compounds 1a and $\mathbf{2}$. All the data above led us to identified the structure of $\mathbf{1}$ as (20S)-protopanaxadiol 3-O-(6-O-malonyl- $\beta$-D-glucopyranosyl $(1 \rightarrow 2)-\beta$-D-glucopyranoside)-20- $O$ - $\beta$-D-xylopyranosyl( $1 \rightarrow 3$ )$\beta$-D-glucopyranosyl $(1 \rightarrow 6)-\beta$-D-glucopyranoside, which we have named malonylginsenoside $\mathrm{Ra}_{3}$.

\section{Experimental}

\subsection{General}

The ${ }^{1} \mathrm{H}$ - and ${ }^{13} \mathrm{C}-\mathrm{NMR}$ spectra were measured on a Bruker Avance DRX 500 NMR spectrometer, using TMS as an internal standard. Chemical shifts $(\delta)$ are expressed in parts per million (ppm), with the coupling constants $(J)$ reported in Hertz $(\mathrm{Hz})$. The ESI-MS spectra were recorded on a triple quadrupole mass spectrometer Quattro (VG Biotech, Altrincham, England) and the HRESI-MS spectra on a Bruker FT-ICRMS spectrometer. Column chromatographies were carried out with silica gel $60 \mathrm{M}$ (200-300 mesh), Lichrospher RP-18 (20 $\mu \mathrm{m})$; TLC was performed with silica gel plates (Macherey- 
Nagel, SilG/UV $\mathrm{UV}_{254}, 0.20 \mathrm{~mm}$ ), with spots detected by $\mathrm{UV}_{254}$ and $\mathrm{H}_{2} \mathrm{SO}_{4}(10 \%)$. HPLC were carried out with a Agilent 1100 system.

\subsection{Plant material}

The fresh root of Panax ginseng was collected from Fu-Song, Jilin, China, in August 2003, and identified by one of the authors, Prof. Yi-Nan Zheng. A voucher specimen (ZYC-RS-03-08) has been deposited in College of Chinese Medicinal Material, Jilin Agricultural University.

\subsection{Extraction and isolation}

The root of Panax ginseng $(10 \mathrm{~kg})$ was extracted five times with $\mathrm{MeOH}-\mathrm{H}_{2} \mathrm{O}(4: 1)$, and the extract was concentrated under reduced pressure at $40{ }^{\circ} \mathrm{C}$. The residue $(\sim 2 \mathrm{~kg})$ obtained was suspended in water and subjected to D-101 resin column chromatography, using $\mathrm{MeOH}-\mathrm{H}_{2} \mathrm{O}(0: 1,3: 2)$ as eluted solvent to give total-ginsenoside $(\sim 300 \mathrm{~g})$. The total-ginsenoside was applied to silica gel column and eluted with $\mathrm{CHCl}_{3}-\mathrm{MeOH}-\mathrm{H}_{2} \mathrm{O}(6: 4: 1)$ to yield three fractions $\left(\mathrm{F}_{1}-\mathrm{F}_{3}\right)$. Fraction $\mathrm{F}_{1}$ was further chromatographed on preparative HPLC eluted with gradient $\mathrm{CH}_{3} \mathrm{CN}-\mathrm{H}_{2} \mathrm{O}(20 \%$ to $50 \%)$ to give the known saponins: malonylginsenoside- $\mathrm{Rb}_{1}$ (compound $2,100 \mathrm{mg}$ ), malonylginsenoside- $\mathrm{Rb}_{2}$ (compound 3, $60 \mathrm{mg}$ ), malonylginsenoside-Rc (compound 4, $65 \mathrm{mg}$ ), malonylginsenoside-Rd (compound 5, $42 \mathrm{mg}$ ) and the new saponin malonylginsenoside $\mathrm{Ra}_{3}$ (compound 1, $40 \mathrm{mg}$ ). Compound 1: ${ }^{1} \mathrm{H}-\mathrm{NMR}\left(400 \mathrm{MHz}, 0.5 \mathrm{~mL}\right.$ pyridine- $\left.d_{5}+0.1 \mathrm{~mL} \mathrm{D}_{2} \mathrm{O}, \mathrm{ppm}\right): \delta 0.73(3 \mathrm{H}, s, \mathrm{H}-19), 0.87(3 \mathrm{H}, s, \mathrm{H}-$ 18), 0.95 (3H, $s, \mathrm{H}-30), 0.98$ (3H, $s, \mathrm{H}-29), 1.17$ (3H, $s, \mathrm{H}-28), 1.63$ (3H, $s, \mathrm{H}-21), 1.65$ (3H, $s, \mathrm{H}-26)$, 1.69 (3H, s, H-27), 5.29 (1H, t-like, H-24), $5.11\left(1 \mathrm{H}, d, J=7.2 \mathrm{~Hz}, \mathrm{C}_{20}\right.$-glc-H-1'), $4.93(1 \mathrm{H}, d, J=7.2$ $\mathrm{Hz}, \mathrm{C}_{20}$-glc-H-1'’) 4.85 (1H, $d, J=7.6 \mathrm{~Hz}, \mathrm{C}_{20}$-xyl-H-1','), 4.81 (1H, $d, J=7.8 \mathrm{~Hz}, \mathrm{C}_{3}$-glc-H-1'), 5.19 $\left(1 \mathrm{H}, d, J=7.6 \mathrm{~Hz}, \mathrm{C}_{3}-\mathrm{glc}-\mathrm{H}-1{ }^{\prime}\right)$ ); ${ }^{13} \mathrm{C}-\mathrm{NMR}$ data, see Table 1.

\subsection{Alkaline hydrolysis of compound $\mathbf{1}$}

A solution of $1(20 \mathrm{mg})$ in $\mathrm{MeOH}(3 \mathrm{~mL})$ was treated with $5 \% \mathrm{KOH}-\mathrm{MeOH}(0.1 \mathrm{~mL})$ and the whole mixture was stirred at room temperature $\left(22^{\circ} \mathrm{C}\right)$ for $30 \mathrm{~min}[6]$. The reaction mixture was neutralized with cation exchange resin (SP20ss, Resindion S.R.L., Rome, Italy) and filtered. Removal of the solvent from the filtrate under reduced pressure gave a product which was purified by column chromatography with reversed-phase silica gel (Zorbax $\mathrm{SB}-\mathrm{C}_{18}$ ) to furnish compound 1a, which was determined to be identical with an authentic sample [6] by TLC comparison $\left[\mathrm{CHCl}_{3}-\mathrm{MeOH}-\mathrm{H}_{2} \mathrm{O}\right.$ (65:35:10, lower phase), $n$-BuOH-AcOH-H $\mathrm{H}_{2} \mathrm{O}$ (4:1:5 upper phase)], IR(KBr), MS and ${ }^{13} \mathrm{C}$ NMR spectral comparisons. Compound 1a: IR (KBr) $v_{\max } / \mathrm{cm}^{-1}: 3432,1728,1605,1385$, 1078; ESI-MS [-]: $\mathrm{m} / \mathrm{z}=1239$ [M-H]', 1107 [M-xyl]', 945 [M-glc-xyl]', 783 [M-xyl-2glc-H]', 621 [M-xyl-3glc-H]', 459 [M-xyl-4glc-H] ; ${ }^{1} \mathrm{H}-\mathrm{NMR}\left(400 \mathrm{MHz}, 0.5 \mathrm{~mL}\right.$ pyridine- $\left.d_{5}, \mathrm{ppm}\right): \delta 0.70(3 \mathrm{H}, s, \mathrm{H}-19), 0.84(3 \mathrm{H}, s, \mathrm{H}-$ 18), 0.86 (3H, $s, \mathrm{H}-30), 0.96$ (3H, $s, \mathrm{H}-29), 1.17$ (3H, $s, \mathrm{H}-28), 1.49$ (3H, $s, \mathrm{H}-21), 1.55$ (3H, $s, \mathrm{H}-26)$, $1.58(3 \mathrm{H}, s, \mathrm{H}-27), 5.20(1 \mathrm{H}, t, \mathrm{H}-24), 5.04\left(1 \mathrm{H}, d, J=7.5 \mathrm{~Hz}, \mathrm{C}_{20}-\mathrm{glc}-\mathrm{H}-1\right.$ '), $4.96(1 \mathrm{H}, d, J=7.6 \mathrm{~Hz}$, $\mathrm{C}_{20}$-glc-H-1' ') $4.83\left(1 \mathrm{H}, d, J=7.6 \mathrm{~Hz}, \mathrm{C}_{20}\right.$-xyl-H-1','), $4.80\left(1 \mathrm{H}, d, J=7.8 \mathrm{~Hz}, \mathrm{C}_{3}\right.$-glc-H-1'), 5.26 $\left(1 \mathrm{H}, d, J=7.6 \mathrm{~Hz}, \mathrm{C}_{3}\right.$-glc-H-1'’); ${ }^{13} \mathrm{C}-\mathrm{NMR}$ data, see Table 1. 


\subsection{Acid hydrolysis of compound $\mathbf{1}$}

To determine the stereochemistry of sugar moiety, compound $\mathbf{1}(2.0 \mathrm{mg})$ was refluxed with $6 \mathrm{~N} \mathrm{HCl}$ $(5 \mathrm{~mL})$ at $100{ }^{\circ} \mathrm{C}$ for $2 \mathrm{~h}[14,15]$. The mixture was extracted with $\mathrm{CHCl}_{3}$ to afford the aglycone, and the aqueous layer was neutralized with $\mathrm{Na}_{2} \mathrm{CO}_{3}$ and filtered. The aqueous layer was dried under vacuum and the residue was re-dissolved in $\mathrm{H}_{2} \mathrm{O}$ for sugar analysis by TLC with $n$ - $\mathrm{BuOH}-\mathrm{AcOH}-\mathrm{H}_{2} \mathrm{O}$ (4:1:2) as the solvent. The sample spots were detected by spraying aniline hydrogen phthalate reagent ( $100 \mathrm{~mL} n$-BuOH saturated by $\mathrm{H}_{2} \mathrm{O}, 0.96 \mathrm{~g}$ aniline and $1.66 \mathrm{~g}$ phthalic acid) and heating at $120^{\circ} \mathrm{C}$. DGlucose and D-xylose were used as authentic standards. The absolute configuration of glucose was further determined by chiral GC analysis using a SatoChrom GC and a $0.25 \mathrm{~mm} \times 25 \mathrm{~m}$ Hydrodexb-6TBDM chiral capillary column (Macherey-Nagel, Germany). $\beta$-D-Glucose and $\beta$-D-xylose were used as an authentic GC standard. The aqueous layer residues mentioned above were re-suspended in dichloromethane $(1 \mathrm{~mL})$, and trifluoroacetic anhydride $(50 \mu \mathrm{L})$ was added. The mixtures were allowed to react at room temperature overnight and dried under a stream of nitrogen at room temperature. The sugar derivatives were separated using the following temperature program: inlet temperature was set at $240{ }^{\circ} \mathrm{C}$, with hydrogen carrier gas and a $1 / 20$ split, using nitrogen makeup gas. Column temperatures started at $120^{\circ} \mathrm{C}$, ramped to $220^{\circ} \mathrm{C}$ at $50{ }^{\circ} \mathrm{C} \cdot \mathrm{min}^{-1}$ and were maintained for $12 \mathrm{~min}$.

\section{Conclusion}

A phytochemical investigation on the fresh root of Panax ginseng led to the isolation of a new saponin (20S)-protopanaxadiol 3 -O-(6-O-malonyl- $\beta$-D-glucopyranosyl( $(\rightarrow 2)-\beta$-D-glucopyranoside)20 -O- $\beta$-D-xylopyranosyl $(1 \rightarrow 3)$ - $\beta$-D-glucopyranosyl $(1 \rightarrow 6)-\beta$-D-glucopyranoside $(\mathbf{1})$ along with four known ginsenosides (2-5).

\section{Acknowledgements}

We are grateful to Zhi-Wei Deng (Analytical Center, Beijing Normal University) for measuring the NMR spectra. This work was supported by the grant from National Natural Science Foundation of China (30971885), Major Program of Transgenic Species Development of Ministry of Agriculture of China (2009ZX08009-062B) and Key Projects in the National Science \& Technology Pillar Program during the Eleventh Five-Year Plan Period (2009BADB3B05).

\section{References and Notes}

1. Li, X.G.; Li, X.; Lei, J. Drug Discovery and Traditional Chinese Medicine: Science, Regulation, and Globalization; Kluwer Academic Publishers: Maryland, MD, USA, 2000; pp. 97-109.

2. Xiang, Y.Z.; Shang, H.C.; Gao, X.M.; Zhang, B.L. A comparison of the ancient use of ginseng in traditional Chinese medicine with modern pharmacological experiments and clinical trials. Phytother. Res. 2008, 22, 851-858.

3. Bachran, C.; Bachran, S.; Sutherland, M.; Bachran, D.; Fuchs H. Saponins in tumor therapy. Mini. Rev. Med. Chem. 2008, 8, 575-584. 
4. Yue, P.Y.; Mak, N.K.; Cheng, Y.K.; Leung, K.W.; Ng, T.B.; Fan, D.T.; Yeung, H.W.; Wong, R.N. Pharmacogenomics and the Yin/Yang actions of ginseng: anti-tumor, angiomodulating and steroid-like activities of ginsenosides. Chin. Med. 2007, 15, 6.

5. Tung, N.H.; Song, G.Y.; Park, Y.J.; Kim, Y.H. Two new Dammarane-type saponins from the leaves of Panax ginseng. Chem. Pharm. Bull. 2009, 57, 1412-1414.

6. Sun, G.Z.; Liu, Z.; Li, X.G.; Zheng, Y.N.; Wang, J.Y. Isolation and identification of two malonylginsenosides from the fresh root of Panax ginseng. Chin. J. Anal. Chem. 2005, 33, 1783-1786.

7. Kitagawa, I.; Taniyama, T.; Hayashi, T.; Yoshikawa, M. Malonyl-ginsenosides $\mathrm{Rb}_{1}, \mathrm{Rb}_{2}$, Rc and $\mathrm{Rd}$, four new malonylated dammarane-type triterpene oligosaccharides from ginseng radix. Chem. Pharm. Bull. 1983, 31, 3353-3356.

8. Yamaguchi, H.; Kasai, R.; Matsuura, H.; Tanaka, O.; Fuwa, T. High-performance liquid chromatographic analysis of acidic saponins of ginseng and related plants. Chem. Pharm. Bull.1988, 36, 3468-3473.

9. Liu, Z.; Wang, L.J.; Li, X.; Hu, J.N.; Chen, Y.; Ruan, C.C.; Sun, G.Z. Hypoglycemic effects of malonyl-ginsenosides extracted from roots of Panax ginseng on streptozotocin-induced diabetic mice. Phytother. Res. 2009, 23, 1426-1430.

10. Wang, J.Y.; Li, X.G.; Zheng, Y.N.; Yang, X.W. Isoginsenoside-Rh3, a new triterpenoid saponin from the fruits of Panax ginseng C. A. Mey. J. Asian Nat. Prod. Res 2004, 6, 289-293.

11. Lei, J.; Li, X.; Gong, X.J.; Zheng, Y.N. Isolation, synthesis and structures of cytotoxic ginsenoside derivatives. Molecules 2007, 12, 2140-2150.

12. Ruan, C.C.; Zhang, H.; Zhang, L.X.; Liu, Z.; Sun, G.Z.; Lei, J.; Qin, Y.X.; Zheng, Y.N.; Li, X.; Pan, H.Y. Biotransformation of Ginsenoside Rf to Rh1 by Recombinant $\beta$-Glucosidase. Molecules 2009, 14, 2043-2048.

13. Matsuura, H.; Kasai, R.; Tanaka, O.; Saruwatari, Y.; Kunihiro, K.; Fuwa, T. Further studies on damarane-saponins of ginseng roots. Chem. Pharm. Bull. 1984, 32, 1188-1192.

14. Li, X.; Liu, Z.; Zhang, X.F.; Wang, L.J.; Zheng, Y.N.; Ruan, C.C.; Sun, G.Z. Isolation and characterization of phenolic compounds from the leaves of Salix matsudana. Molecules 2008, 13, 1530-1537.

15. Li, X.; Liu, Z.; Chen, Y.; Wang, L.J.; Zheng, Y.N.; Sun, G.Z.; Ruan, C.C. Rubiacordone A: A new anthraquinone glycoside from the roots of Rubia cordifolia. Molecules 2009, 14, 566-572.

Sample Availability: Samples are available from the authors (contact zh.lianxue@gmail.com).

(C) 2010 by the authors; licensee Molecular Diversity Preservation International, Basel, Switzerland. This article is an open-access article distributed under the terms and conditions of the Creative Commons Attribution license (http://creativecommons.org/licenses/by/3.0/). 